\title{
The impact of different rehabilitation strategies after major events in the elderly: the case of stroke and hip fracture in the Tuscany
} region

\author{
Fabrizio Carinci*†1, Lorenzo Roti ${ }^{\dagger 1}$, Paolo Francesconi ${ }^{\dagger 1}$, Rosa Gini ${ }^{\dagger 1}$, \\ Fabrizio Tediosi ${ }^{\dagger 3}$, Tania Di Iorio ${ }^{\dagger 2}$, Simone Bartolacci ${ }^{\dagger 1}$ and Eva Buiatti ${ }^{\dagger 1}$
} \begin{abstract}
International Health, Basel, Switzerland
Email: Fabrizio Carinci* - research@fabcarinci.net; Lorenzo Roti - lorenzo.roti@arsanita.toscana.it; Paolo Francesconi - paolo.francesconi@arsanita.toscana.it; Rosa Gini - rosa.gini@arsanita.toscana.it; Fabrizio Tediosi - fabrizio.tediosi@unibas.ch; Tania Di Iorio - tania_diiorio@virgilio.it;

Simone Bartolacci - simone.bartolacci@arsanita.toscana.it; Eva Buiatti - eva.buiatti@arsanita.toscana.it

* Corresponding author †Equal contributors
\end{abstract}

Address: ${ }^{1}$ Agenzia Regionale di Sanità della Toscana, Firenze, Italy, ${ }^{2}$ Serectrix Health Systems Research, Pescara, Italy and ${ }^{3}$ Swiss Centre for

Published: 27 June 2007

BMC Health Services Research 2007, 7:95 doi:10.1186/1472-6963-7-95

This article is available from: http://www.biomedcentral.com/l472-6963/7/95

(c) 2007 Carinci et al; licensee BioMed Central Ltd.

This is an Open Access article distributed under the terms of the Creative Commons Attribution License (http://creativecommons.org/licenses/by/2.0), which permits unrestricted use, distribution, and reproduction in any medium, provided the original work is properly cited.
Received: 27 June 2006

Accepted: 27 June 2007

\begin{abstract}
Background: On a regional level, our aims were to describe rehabilitation patterns for elderly patients with stroke and hip fracture and to investigate mortality risk during the 6-month post acute period.

Methods: Data sources included administrative data relative to patients aged $65+$ resident in Tuscany admitted in hospital for stroke or hip fracture between $200 \mathrm{I}$ and 2003, traced up to 3 years before and 6 months following index admission. The study design involves computerized linkage of administrative data, and an exploratory analysis of the association between rehabilitation patterns and 6-month mortality, adjusting for clinical, demographic, and acute-related care characteristics using multivariate Cox regression.

Results: Rehabilitation patterns vary greatly across Tuscany with considerable cost implications. Six month mortality risk for stroke patients is significantly lower among residents of Local Health Authorities where patients are more frequently rehabilitated, specifically in extra-hospital settings.

Conclusion: Our study, targeting two crucial conditions for elderly patients, found a high variability of rehabilitation patterns across a region, albeit coherent between the two pathologies, associated with remarkable differences in average expenditure. Differences in hazard rates for 6month mortality after stroke at population level were also found. These results need to be confirmed and further investigated through a more robust information framework.
\end{abstract}

\section{Background}

National health systems increasingly need to monitor the impact of their policies in order to optimise care. European countries need to identity new solutions for the emerging needs caused by multiple chronic conditions affecting the elderly, frequently as a direct consequence of acute events. Stroke and hip fracture represent major risk factors for the onset of progressive and catastrophic disa- 
bility [1] and high-impact triggers of a range of complications known to be significantly associated with increased mortality [2-4].

Both conditions typically require a mix of medical/rehabilitative services such as inpatient, outpatient and homebased care, whose integration needs to be carefully monitored [5]. Despite all efforts, there is a large variation in terms of utilization, costs, and outcomes of rehabilitation in the elderly following an acute event [2,6-11]. Due to the expanding availability of standardised databases, it is now possible to use computerized data-linkage to conduct a system-wide evaluation of rehabilitation.

Aims of the study are to describe patterns of utilization of rehabilitation services in Tuscany for subjects aged 65 and older, using stroke and hip fracture as index conditions, and to investigate their association with post-acute 6month mortality.

\section{Methods}

\section{The Regional Health Care System}

The study was conducted in the region of Tuscany, Central Italy, with a population of approximately 3.5 million, $23 \%$ aged $65+$ and $11 \%$ over 74 . The regional health care system is organized in 12 Local Health Authorities (LHAs) and 4 independent Hospital Trusts (HT). LHAs organize all health services - hospital care included - while HTs provide highly specialized care. According to the latest regional directive in the field of rehabilitation [12], after an acute episode patients can undergo residential and semi-residential rehabilitation care, either in hospital rehabilitation wards, or extra-hospital rehabilitation facilities, outpatient or home rehabilitation care, with services provided by multidisciplinary teams at extra-hospital rehabilitation facilities or by individual physiotherapists. Regional guidelines also identify three phases of rehabilitative care following acute events: rehabilitation provided during the stay in the acute hospital ward (for stays longer than 10 days only); intensive rehabilitation, provided soon after discharge from the acute hospital ward for 3040 days in the different settings; and extensive rehabilitation, provided, if needed, after intensive rehabilitation by community care services or through admission in a nursing home.

\section{Data Sources}

The available regional administrative databases (hospital discharges, outpatient specialist services, extra-hospital rehabilitation services) and the regional mortality register were linked through a personal unique identifier (tax file number). An ad hoc algorithm was used to check the results of the linkage procedure. Residents in one of the 12 LHAs were excluded from the final analysis due to inaccurate recording.

\section{Study Population}

The study population refers to residents in Tuscany aged at least 65 , discharged from acute hospital wards between $1 / 7 / 2001$ and $30 / 6 / 2003$ with a primary diagnosis of stroke (ICD-9-CM 430, 431, 434, 436) [13-16], never admitted for stroke during the previous three years, or with a primary diagnosis of hip fracture (ICD-9-CM 820821) [17], not admitted with the same diagnosis during the previous 28 days (index admissions).

\section{Study Variables}

Selected demographic, clinical, acute care-related and ecological rehabilitation variables were identified as potential correlates of mortality. Demographic characteristics included age, gender and marital status. Clinical characteristics included major comorbidities, according to diagnoses available from hospital admissions up to three years prior to the index event [18-21], type of stroke (ischemic stroke, subarachnoid haemorrage and intracerebral haemorrhage) and type of hip fracture (intracapsular, extracapsular, other or unspecified). Acute care-related factors included length of stay (LOS) at index admission, admission in stroke unit (for stroke), surgery procedure within 2 days of admission (for hip fracture). Surgery procedures were identified using standard criteria (ICD-9-CM codes $7905,7915,7925,7935,7945,7955,8151,8152)$. Stroke units were identified according to previously defined criteria [22]. We also defined five rehabilitation settings according to the first service provided after discharge from the acute hospital ward: Inpatient Hospital (residential rehabilitation care in hospital rehabilitation wards); Inpatient Facility (residential rehabilitation care in extra-hospital rehabilitation facilities); Outpatient Rehabilitation (semi-residential and outpatient rehabilitation care); Home Rehabilitation; and Hospital Stay with Rehabilitation Procedures (rehabilitation procedures provided in non-rehabilitation acute hospital wards during an hospital admission occurring after discharge from the index admission).

\section{Statistical Analysis}

Univariate statistics and graphical outputs were used to describe rehabilitation services provided after the index event. Percentages are expressed in relation to either the total population experiencing the index event (including in-hospital deaths), or, when appropriate, to the subjects discharged alive. We investigated the association between rehabilitation patterns and 6-month mortality through the definition of an ecological variable classifying LHAs by the average use of rehabilitation services for their residents. A specific plot was used to position LHAs (displayed as a dot with a unique alpha ID) on a bivariate plan showing the proportion of patients rehabilitated after discharge (X axis) vs the proportion of subjects undergoing inpatient rehabilitation among those rehabil- 
itated ( $\mathrm{Y}$ axis). A superimposed grid was used to define four quadrants based on the median values of the proportion of rehabilitated patients overall and in hospital: (I) both below the median, (II) overall below the median and in hospital above the median, (III) overall above the median and in hospital below the median, and (IV) both above the median.

Proportional hazards regression [23] was the basis of multivariate survival analysis. Multiple observations per patient were used to take into account time varying covariates. Times at risk were computed starting from the $3^{\text {rd }}$ quartile of LOS in the acute wards. This way we excluded early deaths, both in-hospital and post-discharge not relevant for post-acute rehabilitation, while defining a common start-up for the follow-up of all patients. Multivariate Cox regression analysis was used to evaluate the independent association between rehabilitation and increased mortality, adjusting for all other individual characteristics. Final models were produced forcing in all variables considered clinically meaningful as fixed effects, including individual-level covariates (demographic, clinical and acute care related factors) and an ecological rehabilitation variable [24]. All analyses were performed using STATA [25], version 8.2.

\section{Ethics and consent}

Data processing and statistical analysis have been conducted at the Regional Offices of Agenzia Regionale di Sanità della Toscana. As a technical and scientific structure of the Regional Government, the Agenzia has the right to use administrative databases and publish summary reports (Regional Law n.28 10 th $^{\text {th }}$ July 2006, Art.3.1.1.b) and is granted direct access to identifiable individual health data (Art.19.1.2).

\section{Results}

Population under study ( $\mathrm{N}=12$ LHAs), rehabilitation settings and 6-month mortality rates are described in Figure 1. Out of the 13,354 subjects with stroke identified in the reference time interval, $16.7 \%$ died during the index admission (83.9\% of whom before the $3^{\text {rd }}$ quartile LOS) and further $15.0 \%$ within 180 days after discharge. For hip fracture, 12,389 subjects were extracted, with $3.1 \%$ deaths recorded in hospital $(76.7 \%$ of whom before the 3rd quartile LOS) and further $13.8 \%$ within 180 days after discharge. Stroke patients were slightly younger than subjects experiencing hip fractures, with a higher prevalence of males. Average LOS was longer among subjects with hip fractures, albeit less variable. In terms of acute care, 549 patients with stroke $(4.1 \%)$ were admitted to stroke units while 2,801 patients with hip fracture $(22.6 \%)$ underwent surgery within 2 days from admission. Overall, a lower proportion of stroke patients discharged alive underwent some form of rehabilitation compared to same with hip fracture (25.6 vs 45.5\%), but the rehabilitated patients (with the exception of rehabilitation procedures in ordinary acute care, identified only for hip fracture patients) were similarly distributed in the rehabilitation settings across the two events. Also the median delay between discharge and rehabilitation were similar across the two events, except for inpatient facility care provided to hip fracture patients with a median delay of 4 days vs 2 weeks for stroke. There was no delay for hospital rehabilitation, 15-16 days for home-based care, 35-38 days for outpatient care.

In both cases, risk of death during the six-month followup was higher for patients who did not undergo any rehabilitation (approx 20\%), intermediate for subjects rehabilitated in hospital or at home (between 10-15\%), lower for those rehabilitated in outpatient or inpatient settings (below 5\%).

In stroke, the average economic value of rehabilitation services per rehabilitated subject was $8,860 €$ for inpatient rehabilitation, 5,025€ for inpatient facility, $489 €$ for outpatient and $344 €$ for home-based care. Average economic values for hip fracture were $25 \%$ lower for each service, although similarly more expensive for inpatient care than other solutions.

Figure 2 shows the variability across the region based on 11 LHAs with accurate data. There is a large variation in the proportions of patients undergoing rehabilitation, and of those rehabilitated in hospital among those rehabilitated, with considerable cost implications. Variation across LHAs is two-fold for the average proportion of rehabilitated patients and eight-fold for the proportion of subjects rehabilitated that has received rehabilitation in hospital. The majority of dots in the plot lie in the same quadrant across the two diseases: only two LHAs (B, I) appear under different quadrants, with just one (I) crossing non-adjacent ones, i.e. classifying differently according to both variables. Such variability is also reflected by economic values, showing a three-fold to seven-fold variation in the mean estimated cost of rehabilitation services per patient discharged alive for stroke and hip fracture respectively. Remarkably, LHAs in quadrant IV present by far the highest costs, almost double (for stroke) or triple (for hip fracture) those of LHAs in quadrant III.

Table 1 presents the general demographic, clinical, acutecare and ecological rehabilitation characteristics of $\mathrm{N}=$ 10,622 subjects with stroke and $N=11,720$ subjects with hip fracture, resident in the 11 LHAs entering the analysis, alive at the $3^{\text {rd }}$ quartile of the LOS after index admission.

Adjusted estimates of HRs with 95\% CIs are summarized in Table 2. Several individual-level demographic, clinical 


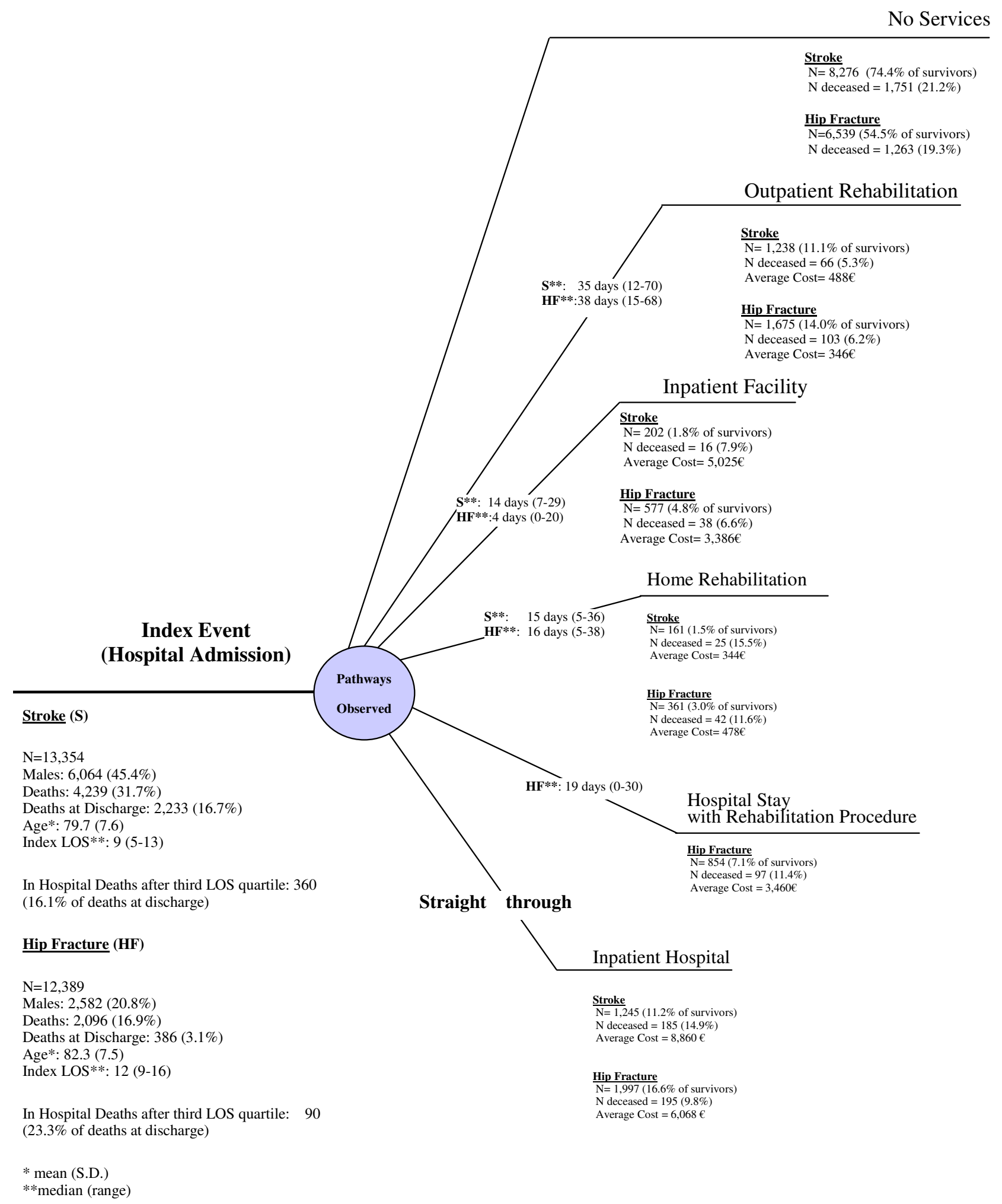

Figure I

Rehabilitation Patterns after Stroke/Hip Fracture, I2 LHAs, Tuscany Jul 0I-Jun 03. 

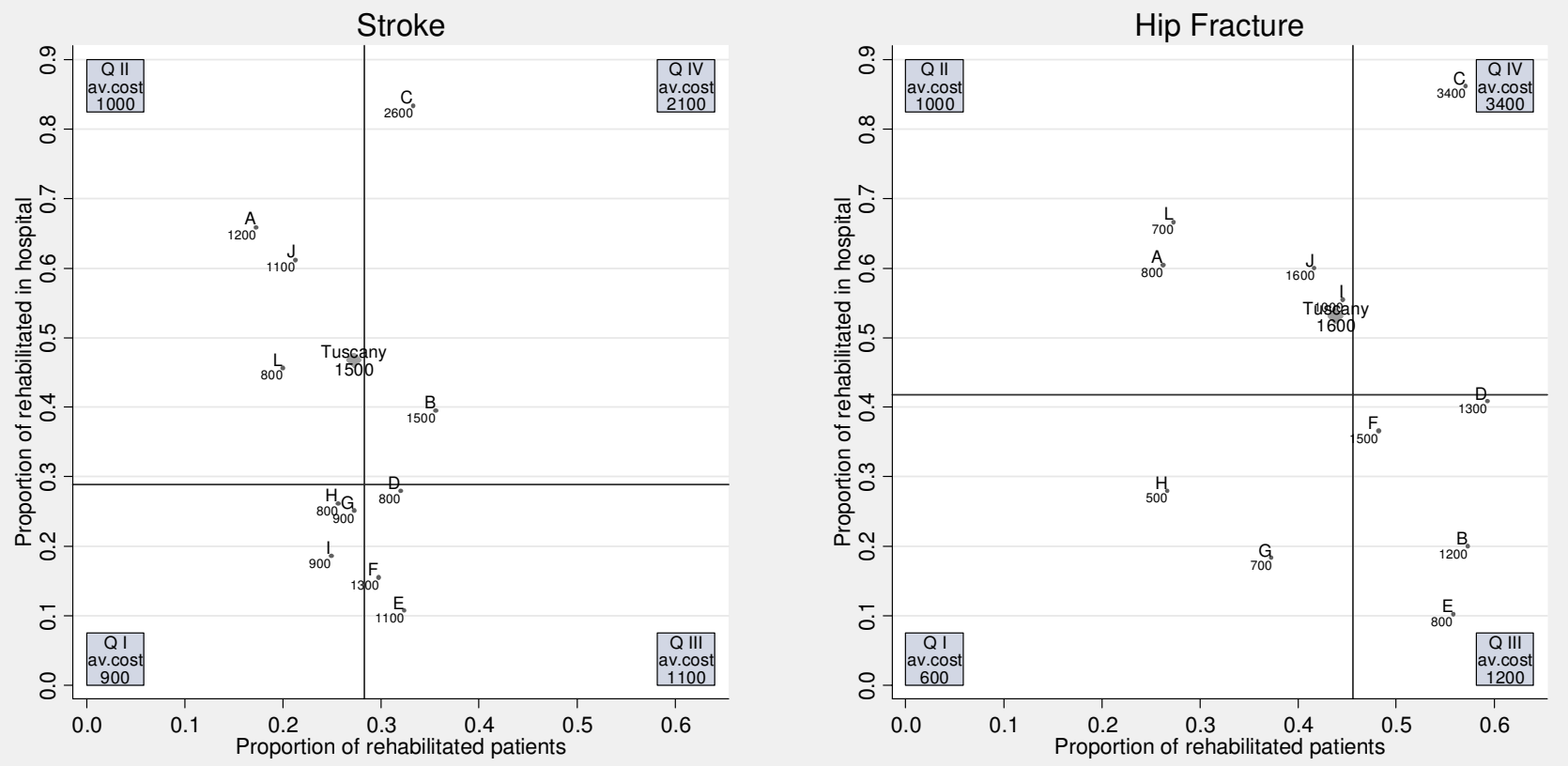

Figure 2

Observed proportion of rehabilitated patients (out of those discharged alive) and of rehabilitated in hospital (out of those rehabilitated) among residents in II LHAs in Tuscany discharged alive for stroke/hip fracture between I/7/0I and 30/6/03. Dots are LHAs with alphabetic ID and average cost per discharged patient. Label box: quadrant ID and average cost.

and acute care-related factors are associated with increased risk of death during the 6-month follow-up period. Males (for hip fractures), patients previously hospitalised with diagnoses of severe disease, patients with haemorrhagic stroke or subarachnoid haemorrhage, and patients with longer LOS had an increased risk of death. Stroke patients admitted to stroke units and hip fractures undergoing surgery within 2 days from admission were associated to a decreased mortality.

Stroke patients resident in LHAs with a higher proportion of rehabilitated patients (quadrants III, IV) showed a reduced risk of death compared to subjects resident in LHAs with a lower proportion of rehabilitated patients, among whom also the use of in hospital rehabilitation was reduced (quadrant I). However, such reduction was small, not significant (HR 0.91, p-value 0.12) for patients resident in LHAs where most rehabilitation occurs in hospital (quadrant IV), while relatively high and statistically significant (HR 0.73, p-value < 0.01) for patients resident in LHAs where most rehabilitation occurs in extra-hospital settings (quadrant III). Among hip fractures, our data did not show any significant association between the average rehabilitation patterns found in LHAs and 6-month mortality.

\section{Discussion}

According to our study, approximately 6,500 and 6,000 hospital admissions occur every year in Tuscany for firstever strokes and hip fracture, matching results obtained using administrative databases $[26,27]$ and populationbased studies [28]. Similarly to other reports [29,30], we found that nearly $17 \%$ patients admitted for stroke and $3 \%$ of those admitted for hip fracture die during hospitalisation. Additional 15\% approximately does not survive beyond 6 months following discharge.

The association found between demographic, clinical and acute care-related factors and 6-months mortality is consistent with recent studies and supports the validity of our data. A large European project in stroke [4] showed a more than two-fold risk of death for patients aged over 75, while another conducted in Australia reported age, prestroke disability and haemorrhagic stroke among the major determinants of stroke mortality at one year [31]. Reports from the UK [32] and US [9] on hip fractures similarly showed an increase in risk for age and males, and a Canadian study additionally also showed significance of pre-existent comorbidities [33]. The higher risk of diabetic patients among subjects with hip fractures confirms previous results [8]. The protective effect of hypertension could 
Table I: General Characteristics of patients admitted for Stroke (S) and Hip Fracture (HF)

\begin{tabular}{|c|c|c|c|c|}
\hline \multirow{2}{*}{$\begin{array}{l}\text { Dimension } \\
\text { Variable }\end{array}$} & \multicolumn{2}{|c|}{ Stroke } & \multicolumn{2}{|c|}{ Hip Fracture } \\
\hline & Entering analysis & Dead within 6 months & Entering analysis & Dead within 6 months \\
\hline \multicolumn{5}{|l|}{ Categories } \\
\hline $\mathbf{N}$ & 10622 & $1383(13.0)$ & 11720 & $1407(12.0)$ \\
\hline \multicolumn{5}{|l|}{ Demographic } \\
\hline \multicolumn{5}{|l|}{ Age } \\
\hline $65-74$ & 3188 & $200(6.3)$ & 1992 & $101(5.1)$ \\
\hline $75-79$ & 2470 & $221(8.9)$ & 2284 & $17 \mid(7.5)$ \\
\hline $80-84$ & 2281 & $312(13.7)$ & 2713 & $265(9.8)$ \\
\hline$\geq 85$ & 2683 & $650(24.2)$ & 4731 & $870(18.4)$ \\
\hline \multicolumn{5}{|l|}{ Gender } \\
\hline Female & 5725 & $812(14.2)$ & 9370 & $997(10.6)$ \\
\hline Male & 4897 & 571 (1I.7) & 2350 & $410(17.4)$ \\
\hline \multicolumn{5}{|l|}{ Marital Status } \\
\hline Married & 5876 & $650(11.1)$ & 4791 & $502(10.5)$ \\
\hline Single & 890 & $118(13.3)$ & 1239 & $158(12.8)$ \\
\hline Divorced/separated/widow & 2976 & $521(17.5)$ & 4516 & 627 (13.9) \\
\hline Missing & 880 & $94(10.7)$ & 1174 & $120(10.2)$ \\
\hline \multicolumn{5}{|l|}{ Clinical } \\
\hline \multicolumn{5}{|l|}{ Major Comorbidities } \\
\hline Cong. Heart Failure & 901 & $192(21.3)$ & 734 & $169(23.0)$ \\
\hline Cardiac arrhythmias & 2001 & $378(18.9)$ & 645 & $128(19.8)$ \\
\hline Valvular disease & 495 & $76(15.4)$ & 296 & $47(15.9)$ \\
\hline Cardiac & 2754 & $491(17.8)$ & 1314 & $257(19.6)$ \\
\hline Peripheral vascular disease & 639 & $98(15.3)$ & 335 & $72(21.5)$ \\
\hline Hypertension & 4928 & $505(10.2)$ & 2088 & $240(11.5)$ \\
\hline Neurological & 482 & $80(16.6)$ & 376 & $63(16.8)$ \\
\hline Chronic pulmonary disease & 993 & $158(15.9)$ & 790 & $147(18.6)$ \\
\hline Diabetes & 1965 & $24 \mid(12.3)$ & 892 & $130(14.6)$ \\
\hline Renal Failure & 424 & $92(21.7)$ & 267 & $56(21.0)$ \\
\hline Liver disease & 201 & $29(14.4)$ & 236 & $40(16.9)$ \\
\hline Cancer & 672 & $175(26.0)$ & 556 & $116(20.9)$ \\
\hline Anemia & 339 & $81(23.9)$ & 353 & $50(14.2)$ \\
\hline \multicolumn{5}{|l|}{ Stroke Type } \\
\hline Ischaemic & 9049 & II 48 (12.7) & & \\
\hline Subarachnoid Haemorrhagic & 211 & $20(9.5)$ & & \\
\hline Haemorrhagic & 1362 & $215(15.8)$ & & \\
\hline \multicolumn{5}{|l|}{ Fracture Type } \\
\hline Intracapsular & & & 5613 & $667(11.9)$ \\
\hline Extracapsular & & & 5150 & $632(12.3)$ \\
\hline Other/unspecified & & & 957 & $108(11.3)$ \\
\hline \multicolumn{5}{|l|}{ Acute Care related } \\
\hline \multicolumn{5}{|l|}{ Index LOS Category } \\
\hline$<=$ upper quartile & 8243 & $894(10.8)$ & 9152 & $1082(11.8)$ \\
\hline > upper quartile & 2379 & $489(20.6)$ & 2568 & $325(12.7)$ \\
\hline \multicolumn{5}{|l|}{ Admitted Stroke Unit at IstS } \\
\hline Yes & 483 & $43(8.9)$ & & \\
\hline No & 10139 & $1340(12.5)$ & & \\
\hline \multicolumn{5}{|l|}{ Surgery Procedure at $\mathrm{I}^{\text {st }} \mathrm{HF}$} \\
\hline within 2 days & & & 2692 & $275(10.2)$ \\
\hline after 2 days & & & 9028 & $1132(9.7)$ \\
\hline \multicolumn{5}{|l|}{ Rehabilitation } \\
\hline \multicolumn{5}{|l|}{ LHA Rehabilitation Rates } \\
\hline -Overall,-Hospital (Q-I) & 2519 & $329(13.1)$ & 1640 & $186(11.3)$ \\
\hline -Overall,+Hospital (Q-II) & 2196 & $308(14.0)$ & 3562 & $435(12.2)$ \\
\hline +Overall,-Hospital (Q-III) & 2086 & 239 (11.5) & 3311 & $383(11.6)$ \\
\hline +Overall,+Hospital (Q-IV) & 3821 & $507(13.3)$ & 3207 & $403(12.6)$ \\
\hline
\end{tabular}


be due to over-reporting of this condition among cases presenting better conditions overall.

As far as acute care is concerned, our results are consistent with a meta-analysis showing a $17 \%$ one-year mortality reduction for stroke patients admitted in stroke units [34], a clear advantage very recently confirmed on field by a large observational follow-up study conducted on a sample of 11572 Italian acute stroke patients [35]. However, in Tuscany only $4 \%$ of the aged population affected by stroke is admitted to a stroke unit.

The mortality risk reduction found for hip fractures promptly operated after admission, inconsistently reported by others [36,37], is of interest, although it could be due to better overall conditions of patients eligible for prompt intervention.

Our study highlighted several important aspects related to rehabilitation services.

Overall, during the 6-months follow-up period, about $25 \%$ stroke and $45 \%$ hip fracture survivors used some kind of rehabilitative services. We found a high variation in the use of rehabilitation by LHA of residency, particularly for the fraction of rehabilitation provided in hospital.

The patterns of rehabilitation settings are quite consistent across the two acute events, reflecting the different availability of services provided by LHAs across the region, which in turn are the result of long and complex processes rather than of current evidence-based choices.

From an economic point of view, the high variability of expenditure found across LHAs raises great concern about equity issues around the provision of rehabilitation services. Similar differences in rehabilitation patterns appear in other European regions and can be very hard to modify.

Our results highlight the need for carefully assessing the cost-effectiveness of rehabilitation strategies for patients experiencing stroke and hip fracture. While reducing mortality is not the primary aim of rehabilitation services in general, massive practice of in-hospital rehabilitation was expected to show a protective effect at the population level. In our analysis, subjects with stroke - but not with hip fracture - are instead less likely to die during the sixmonth post acute period if they live in areas where actually a relatively large proportion of patients undergo rehabilitation services, but more often in extra-hospital settings.

The result cannot be fully explained with the available data, so that further investigations are needed to evaluate outcomes of expensive options such as in hospital rehabilitation, for which we still lack a clear evidence of survival improvement at the population level.

Finally, several limitations of our study are worth to be outlined.

Firstly, the validity of this report is strictly related to the secondary source used. Computerized health records may be still partially incomplete and some of the variation found may be due to the quality of data. To improve quality of this study, we excluded all records relative to one LHA not recording accurately.

Secondly, clinical information included in computerized records may not allow an adequate adjustment for the severity of the disease. This may be due partly to incorrect and/or incomplete clinical information, for which we have extended our data collection retrospectively to include all diagnoses available up to three years before the acute event. On the other hand, it can be virtually impossible to isolate the effect of individual characteristics that can be directly related to the health services provided. In our case, at the individual level, the relation between different rehabilitation treatment and 6-month mortality may be confounded by the tendency to offer specific treatment to patients characterized by specific clinical conditions that are in turn associated to the outcome. Consistently with the available literature [24], we have taken into account such "confounding by indication" by using an ecological treatment variable (LHA rehabilitation patterns), a valid solution if we make the reasonable assumption of a similar case-mix for stroke and hip fracture across LHAs.

Thirdly, statistical significance of the association found must be interpreted with caution for methodological reasons. The main results of the study are prone to the "ecological fallacy", i.e. some unmeasured individual characteristics, or other influential ecological confounders may be the actual determinants of the association found between rehabilitation patterns and mortality. To take into account this possible fallacy, we have used all information available related to the individual subject, at the same time providing an interpretation in terms of organizational factors that is highly plausible.

Fourthly, economic values are only indirectly estimated, based on the regional tariff lists, which are only a proxy of real health care costs. Furthermore, costs of outpatient services did not include pharmaceuticals. In the present study we have approached the economic analysis only through a rough estimate of the amount of resources spent for rehabilitation, that are certainly underestimated to some extent for the outpatient setting. 
Table 2: Results of Cox Multivariate Regression

\begin{tabular}{|c|c|c|c|c|}
\hline \multirow{2}{*}{$\begin{array}{l}\text { Dimension } \\
\text { Variable }\end{array}$} & \multicolumn{2}{|c|}{ Stroke } & \multicolumn{2}{|c|}{ Hip Fracture } \\
\hline & H.R. $(95 \%$ c.i. $) *$ & $P$ value & H.R. (95\% c.i.)* & $P$ value \\
\hline \multicolumn{5}{|l|}{ Categories } \\
\hline \multicolumn{5}{|l|}{ Demographic } \\
\hline \multicolumn{5}{|l|}{ Age } \\
\hline \multicolumn{5}{|l|}{$65-74$ (R.C) } \\
\hline $75-79$ & $1.52(1.31-1.78)$ & $<0.001$ & $1.62(1.30-2.03)$ & $<0.001$ \\
\hline $80-84$ & $2.08(1.79-2.41)$ & $<0.001$ & $2.08(1.68-2.57)$ & $<0.001$ \\
\hline$\geq 85$ & $3.76(3.27-4.32)$ & $<0.001$ & $4.13(3.39-5.01)$ & $<0.001$ \\
\hline \multicolumn{5}{|l|}{ Gender } \\
\hline Females & $1.04(0.94-1.14)$ & 0.44 & $1.85(1.65-2.07)$ & $<0.001$ \\
\hline \multicolumn{5}{|l|}{ Marital Status } \\
\hline \multicolumn{5}{|l|}{ Married (R.C.) } \\
\hline Single & $1.12(0.95-1.31)$ & 0.19 & $1.24(1.04-1.46)$ & $<0.05$ \\
\hline Divorced/separated/widow & $1.12(1.01-1.24)$ & $<0.05$ & $1.25(1.12-1.41)$ & $<0.001$ \\
\hline Missing & $0.96(0.81-1.14)$ & 0.64 & $0.98(0.81-1.18)$ & 0.80 \\
\hline \multicolumn{5}{|l|}{ Clinical } \\
\hline \multicolumn{5}{|l|}{ Major Comorbidities } \\
\hline Cong. Heart Failure & $1.61(1.36-1.90)$ & $<0.001$ & $1.62(1.25-2.10)$ & $<0.001$ \\
\hline Cardiac arrhythmias & $1.47(1.22-1.78)$ & $<0.001$ & $1.20(0.95-1.53)$ & 0.13 \\
\hline Valvular disease & $\mathrm{I} .07(0.87-\mathrm{I} .32)$ & 0.53 & $1.21(0.93-1.59)$ & 0.16 \\
\hline Cardiac & $0.78(0.63-0.97)$ & $<0.05$ & $1.03(0.77-1.38)$ & 0.83 \\
\hline Peripheral vascular disease & $1.21(1.02-1.43)$ & $<0.05$ & $1.48(1.18-1.85)$ & $<0.05$ \\
\hline Hypertension & $0.69(0.63-0.76)$ & $<0.001$ & $0.84(0.73-0.95)$ & $<0.05$ \\
\hline Neurological & $1.05(0.87-1.27)$ & 0.58 & $1.38(1.09-1.75)$ & $<0.05$ \\
\hline Chronic pulmonary disease & $1.15(1.00-1.31)$ & $<0.05$ & $1.18(1.01-1.39)$ & $<0.05$ \\
\hline Diabetes & I.II (0.99-1.24) & 0.07 & $1.22(1.04-1.45)$ & $<0.05$ \\
\hline Renal Failure & $1.43(1.20-1.70)$ & $<0.001$ & $1.34(1.06-1.70)$ & $<0.05$ \\
\hline Liver disease & $1.33(0.97-1.80)$ & 0.07 & $1.70(1.28-2.24)$ & $<0.001$ \\
\hline Cancer & $2.17(1.90-2.48)$ & $<0.001$ & $1.80(1.52-2.14)$ & $<0.001$ \\
\hline Anemia & $1.13(0.93-1.37)$ & 0.22 & $1.04(0.82-1.33)$ & 0.72 \\
\hline \multicolumn{5}{|l|}{ Stroke Type } \\
\hline \multicolumn{5}{|l|}{ Ischaemic (R.C.) } \\
\hline Subarachnoid Haemorrhagic & $1.36(1.03-1.79)$ & $<0.05$ & & \\
\hline Haemorrhagic & $1.34(1.19-1.50)$ & $<0.001$ & & \\
\hline \multicolumn{5}{|l|}{ Fracture Type } \\
\hline \multicolumn{5}{|l|}{ Intracapsular (R.C.) } \\
\hline Extracapsular & & & $1.03(0.93-1.14)$ & 0.55 \\
\hline Other/unspecified & & & I.II (0.93-1.32) & 0.26 \\
\hline \multicolumn{5}{|l|}{ Acute Care related } \\
\hline Index LOS Category > third quartile & $2.93(2.68-3.20)$ & $<0.001$ & $1.27(1.14-1.42)$ & $<0.001$ \\
\hline Admitted in Stroke Unit at at IstS & $0.72(0.55-0.94)$ & $<0.05$ & & \\
\hline Surgery Procedure at at Ist HF within 2 days & & & $0.82(0.72-0.93)$ & $<0.05$ \\
\hline \multicolumn{5}{|l|}{ Rehabilitation } \\
\hline \multicolumn{5}{|l|}{ LHA Rehabilitation Rates } \\
\hline \multicolumn{5}{|l|}{-Overall,-Hospital (Q-I) (R.C.) } \\
\hline -Overall,+Hospital (Q-II) & $1.07(0.95-1.22)$ & 0.27 & $1.13(0.97-1.33)$ & 0.12 \\
\hline +Overall,-Hospital (Q-III) & $0.73(0.64-0.83)$ & $<0.001$ & $0.99(0.84-1.16)$ & 0.87 \\
\hline +Overall,+Hospital (Q-IV) & $0.91(0.82-1.02)$ & 0.12 & $1.04(0.89-1.22)$ & 0.61 \\
\hline
\end{tabular}

* longitudinal estimates from proportional hazards regression on the outcome of interest 


\section{Conclusion}

There is a need for improved local policies for the optimal delivery of health services.

Our study, targeting two crucial conditions for elderly patients e.g. stroke and hip fracture, found a high variability of rehabilitation patterns across Tuscany, albeit coherent between the two pathologies, associated with remarkable differences in average expenditure. Differences in hazard rates for 6-month mortality after stroke at population level were also found, with significantly lower rates for those resident in areas where rehabilitation is provided often but in an extra-hospital setting.

The methodology presented in this report can be used and further refined to investigate population outcomes while comparing relative strengths and weaknesses of alternative rehabilitation strategies. However, these results need to be confirmed by a more robust information framework, in order to avoid possible ecological fallacy

A better assessment of rehabilitation policies requires the construction of composite indicators and the collection of ad hoc longitudinal data. More studies are needed to incorporate a range of outcomes properly measured, e.g. the improvement of functional status and the actual costs of health services over multiple diseases.

\section{Competing interests}

The author(s) declare that they have no competing interests.

\section{Authors' contributions}

FC designed the study and statistical analyses, initiating and coordinating the preparation of the manuscript; LR participated in the design of the study and preparation of the manuscript; PF participated in the design of the study and drafting the manuscript; RG participated in the design of the study and performed data transformation and all statistical analyses, developing all STATA software; FT participated in the design of the study and drafted the economic analysis; TDI performed systematic search of the literature; SB performed data extraction and computerized linkage from the regional database; EB conceived, designed and coordinated the study, and participated in drafting the manuscript.

All authors read and approved the final manuscript.

\section{Acknowledgements}

The present study was made possible thanks to the availability of internal resources and funds provided by Agenzia Regionale di Sanità della Toscana.

\section{References}

I. Guralnik JM, Ferrucci L, Balfour JL, Volpato S, Di lorio A: Progressive versus catastrophic loss of the ability to walk: implica- tions for the prevention of mobility loss. J Am Geriatr Soc 200I, 49(II): 1463-70.

2. Grieve R, Hutton J, Bhalla A, Rastenyte D, Ryglewicz D, Sarti C, Lamassa M, Giroud M, Dundas R, Wolfe CD: A comparison of the costs and survival of hospital-admitted stroke patients across Europe. Stroke 200I, 32(7): |684-91.

3. Marks R, Allegrante JP, Ronald MacKenzie C, Lane JM: Hip fractures among the elderly: causes, consequences and control. Ageing Res Rev 2003, 2(I):57-93.

4. Bhalla A, Grieve R, Tilling K, Rudd AG, Wolfe CD: BIOMED II European Study of Stroke Care, Older stroke patients in Europe: stroke care and determinants of outcome. Age Ageing 2004, 33(6):618-24.

5. Cameron I, Crotty M, Currie C, Finnegan T, Gillespie L, Gillespie W, Handoll H, Kurrle S, Madhok R, Murray G, Quinn K, Torgerson D: Geriatric rehabilitation following fractures in older people: $a$ systematic review. Health Technol Assess 2000, 4(2): I- III. i-iv

6. Wolfe $C D$, Tilling K, Rudd A, Giroud M, Inzitari D: Variations incare and outcome in the first year after stroke: a Western and Central European perspective. J Neurol Neurosurg Psychiatry 2004, 75( ( 2): 1702-6.

7. Rudd AG, Irwin P, Rutledge Z, Lowe D, Wade DT, Pearson M: Regional variations in stroke care in England, Wales and Northern Ireland: results from the National Sentinel Audit of Stroke. Royal College of Physicians Intercollegiate Stroke Working Party. Clin Rehabil 200I, I5(5):562-72.

8. Cameron ID, Kurrle SE: Rehabilitation and older people. Med J Aust 2002, I77(7):387-9I.

9. Hannan EL, Magaziner J, Wang JJ, Eastwood EA, Silberzweig SB, Gilbert M, Morrison RS, McLaughlin MA, Orosz GM, Siu AL: Mortality and locomotion 6 months after hospitalization for hip fracture: risk factors and risk-adjusted hospital outcomes. JAMA 200I, 285(2I):2736-42.

10. Ottenbacher KJ, Smith PM, Illig SB, Linn RT, Ostir GV, Granger CV: Trends in length of stay, living setting, functional outcome, and mortality following medical rehabilitation. JAMA 2004, 292(14): 1687-95.

II. Megherbi SE, Milan C, Minier D, Couvreur G, Osseby GV, Tilling K, Di Carlo A, Inzitari D, Wolfe CD, Moreau T, Giroud M: European BIOMED Study ofStroke Care Group Association between diabetes and stroke subtype on survival and functional outcome 3 months after stroke: data from the European BIOMED Stroke Project. Stroke 2003, 34(3):688-94.

12. Regione Toscana Department of Health Services: Web Portal. [http://www.arsanita.toscana.it]. [accessed 6/9/2005]

13. Health Care Financing Administration: International Classification of Diseases, 9th Revision, Clinical Modification (ICD-9CM). DHHS Publication No. (PHS) 80-1260; 2005.

14. Ellekjaer $\mathrm{H}$, Holmen J, Kruger $\mathrm{O}$, Terent $\mathrm{A}$ : Identification of incident stroke in Norway: hospital discharge data compared with a population-based stroke register. Stroke 1999, 30(I):56-60.

15. Reker DM, Rosen AK, Hoenig H, Berlowitz DR, Laughlin J, Anderson L, Marshall CR, Rittman M: The hazards of stroke case selection using administrative data. Med Care 2002, 40(2):96-104.

16. Tirschwell DL, Longstreth WT Jr: Validating administrative datain stroke research. Stroke 2002, 33(10):2465-70.

17. Leslie WD, Derksen S, Metge C, Lix LM, Salamon EA, Wood Steiman $P$, Roos LL: Fracture risk among First Nations people: a retrospective matched cohort study. CMAJ 2004, I I (8):869-73.

18. Elixhauser A, Steiner C, Harris DR, Coffey RM: Comorbidity measures for use with administrative data. Med Care 1998, 36(I):8-27.

19. Southern DA, Quan H, Ghali WA: Comparison of the Elixhauser andCharlson/Deyo methods of comorbidity measurement in administrative data. Med Care 2004, 42(4):355-60.

20. Stukenborg G], Wagner DP, Connors AF Jr: Comparison of the performance of two comorbidity measures, with and without information from prior hospitalizations. Med Care 200I, 39(7):727-39.

21. Quan H, Parsons GA, Ghali WA: Validity of information on comorbidity derived from ICD-9-CCM administrative data. Med Care 2002, 40(8):675-85.

22. Sterzi R, Micieli G, Candelise L, PROSIT Collaborators: Assessment of regional acute stroke unit care in Italy: the PROSIT study. Cerebrovasc Dis 2003, I 5(SuppI I): 16-8. 
23. Cox D, Oakes D: Analysis of Survival Data. London: Chapman and Hall; 1984.

24. Johnston SC: Combining ecological and individual variables to reduce confounding by indication: case study-subarachnoid hemorrhage treatment. J Clin Epidemiol 2000, 53(I 2): |236-4I.

25. STATA Corporation: STATA Reference Manual. Release 8.0, edn. College Station, Tx: STATA Corporation; 2003.

26. De Luca A, Agabiti N, Fiorelli M, Sacchetti ML, Tancioni V, Picconi O, Cardo S, Guasticchi G: Implementation of a surveillance system for stroke based on administrative and clinical data in the Lazio region (Italy): methodological aspects. Ann lg 2003, I5(3):207-| 4

27. Rossini M, Piscitelli P, Fitto F, Camboa P, Angeli A, Guida G, Adami S: Incidence and socioeconomic burden of hip fractures in Italy. Reumatismo 2005, 57(2):97-102.

28. Di Carlo A, Baldereschi M, Gandolfo C, Candelise L, Ghetti A, Maggi S, Scafato E, Carbonin P, Amaducci L, Inzitari D, ILSA Working Group: Stroke in an elderly population: incidence and impact on survival and daily function. The Italian Longitudinal Study on Aging. Cerebrovasc Dis 2003, I6(2): | $4 \mid-50$.

29. Spolaore P, Brocco S, Fedeli U, Visentin C, Schievano E, Avossa F, Milan G, Toso V, Vanuzzo D, Pilotto L, Pessina AC, Bonita R: Measuring accuracy of discharge diagnoses for a region-wide surveillance of hospitalized strokes. Stroke 2005, 36(5):|03|-4. Epub 2005 Mar 24

30. Bravata DM, Ho SY, Brass LM, Concato J, Scinto J, Meehan TP: Longterm mortality in cerebrovascular disease. Stroke 2003, 34(3):699-704. Epub 2003 Feb 20

31. Shen Q, Cordato D, Chan DK, Hung WT, Karr M: Identifying the determinants of I-year post-stroke outcomes in elderly patients. Acta Neurol Scand 2006, I I 3(2): I | 4-20.

32. Roche J], Wenn RT, Sahota O, Moran CG: Effect of comorbidities and postoperative complications on mortality after hip fracture in elderly people: prospective observational cohort study. $B M J$ 2005, 33 I(7529): 1374.

33. Jiang HX, Majumdar SR, Dick DA, Moreau M, Raso J, Otto DD, Johnston DW: Development and initial validation of a risk score for predicting in-hospital and I-year mortality in patients with hip fractures. J Bone Miner Res 2005, 20(3):494-500.

34. Stroke Unit Trialists' Collaboration: Collaborative systematic review of the randomised trials of organised inpatient (stroke unit) care after stroke. BM] 1997, 3 14(7088): II5I-9.

35. Candelise L, Gattinoni M, Bersano A, Micieli G, Sterzi R, Morabito A, PROSIT Study Group: Stroke-unit care for acute stroke patients: an observational follow-up study. Lancet 369(9558):299-305. 2007 Jan 27

36. Casaletto JA, Gatt R: Post-operative mortality related to waiting time for hip fracture surgery. Injury 2004, 35(2): I | 4-20.

37. Franzo A, Francescutti C, Simon G: Risk factors correlated with post-operative mortality for hip fracture surgery in the elderly: a population-based approach. Eur J Epidemiol 2005, 20(I2):985-9|.

\section{Pre-publication history}

The pre-publication history for this paper can be accessed here:

http://www.biomedcentral.com/1472-6963/7/95/prepub http.//www.biomedcentral.com/1472-6963/7/95 